\title{
A Review of Qualitative Comments on a proposed Master's Degree in Emergency Management
}

\author{
Murray Turoff \\ NJIT \& U of Agder, Norway \\ murray.turoff@gmail.com
}

\author{
Victor A. Bañuls \\ Universidad Pablo de Olavide \\ vabansil@upo.es
}

\author{
Lili Yang \\ Loughborough University \\ 1.yang@lboro.ac.uk
}

\begin{abstract}
During 2015, a survey was completed by 373 respondents representing academics and practitioners in Emergency Management. They were asked to evaluate the courses for a Master's degree in Emergency Management with a concentration in Information Systems. This paper reviews the very significant qualitative comments they made about each of the various courses and the program as a whole.
\end{abstract}

\section{Introduction}

The design and execution of the survey on which this paper is based was a result of the activity of an ad hoc committee of ISCRAM (Information Systems for Crisis Response and Management). The survey focused on the need for educational standards, resulting from a paper dealing with the need for standards published in the 2014 ISCRAM Conference [11]. To date there is no professional society that takes responsibility for educational standards for the profession of Emergency Management.

The International Association of Emergency Managers (IAEM) does certify an individual as an Emergency Management professional. They created a Certified Emergency Manager (CEM) process that began accepting applications in 1993 (http://www.iaem.com/page.cfm?p=certification/histor y-of-cem; see also Lucus-McEwen, [1, 4]. In the U.S., traditionally one could become an Emergency Manager (EM) after five years of related work experience. Until 2010, years of experience could be substituted for a college degree for CEM certification, but since 2010, IAEM required a baccalaureate degree as part of the certification requirements. After 2010 a great many current EM professionals decided to obtain degrees on a part time basis, especially if they had no college education. Over the years, this produced over 80 degree programs in the United States

Although information systems are playing an increasingly important role in emergency management, no current master's level standards combine requirements for inter-disciplinary expertise in both Information Systems (IS) and EM. It is natural that ISCRAM took an interest in examining this issue. The initial paper on this topic at ISCRAM pointed out that the current courses and degree programs listed by FEMA [2] implied many possible interdisciplinary relationships for Emergency Management [11]. Six different concentrations in various related areas to Emergency Management were specified there based upon the diversity the courses listed by FEMA. The paper combined the degree programs listed by FEMA into six different possible concentrations.

1. Social and Management Sciences, Public

Administration, and Journalism

2. Information Systems and Computing

3. Engineering, Construction, and Physical Sciences

4. Public Health, Biology, and Medical

5. Geology, Weather, Environment, and Maritime Studies

6. Criminal Justice, Terrorism, and Security

Initially a survey focused on creating a Master's in EM with a concentration in Information Systems and Computing was designed by the ISCRAM educational committee and was distributed to ISCRAM members, and a preliminary report on those results based on 110 responses was presented [7]. Subsequently invitations to participate in the survey were distributed through IAEM and various EM discussion lists, and a much larger and diverse set of respondents was obtained. The survey had ten EM courses and ten courses in IS. The participants were asked to asked to rate the ten EM as a set and also the ten IS as a separate set on the same semantic seven point scale from (1) Should not be in the curriculum, (7) Essential to the Curriculum. There was also a "No Opinion" option in case a participant did not know much about the subject of the course. This latter instruction followed the practice of Delphi Design which has shown that responses weighted by the responders' degree of confidence usually leads to more accurate results $[5,6]$. 
The final number of respondents to the survey in January of 2016 was 558 responses; however, 185 respondents did not answer any questions after they agreed to take the survey. Those responses were deleted from the analyzed data set, yielding 373 usable responses. In total, we received a sizable response from the United States (225), and a reasonable balance between practitioners (265) and academics/researchers (153) in Emergency Management. Note that many of the respondents had experience both as practitioners and academicians/researchers (152). This included practicing EM professionals who had gone back to get a degree in EM. We would have liked a greater international distribution so that we could better examine individual countries, but did have over 74 international participants from over 30 non-U.S.A. countries. There are clearly significant differences between countries in how they treat and handle emergency management that has shown up in other survey type exercises [12].

For all the courses, respondents were given the opportunity to generate comments about each course and some more comprehensive comments. They generated 1,325 comments. This paper focuses on a very select overview of the comments that were made. The criterion for the selection is given below.

There were 750 comments on the individual ten Emergency Management courses and 392 on the ten Information System Courses. There were also 183 comments of a more general nature on the requirements as a whole.

This amount of commentary by the participants was a surprise. There are a great many significant insights in this material and this paper is devoted to presenting the highlights of the comments. The final quantitative data have been analyzed in a separate paper under review. This paper will concentrate on the qualitative comments. Just about every problem or concern that is significant in the field of Emergency Management has a presence in these comments made by the respondents.

We will present each EM course in the order they were voted on from the highest rating to the lowest and then take up the Information System Courses in their voted order. Each course, after the title, shows the numeric vote average and standard deviation on the 1-7 scale. On the scale 1 means that the course should not be in the offered set and 7 means that it is essential to the curriculum. We also show the number of comments made on the course followed by the description (abstract) for the course provided to the participants.

Some of these qualitative comments are similar to those that appeared in the Appendix to the 2014 paper [11] taken from online discussions of professionals in
EM during 2013 and 2014. For each course, we have extracted a small number of comments (3-5) that give an interesting, unusual, and/or significant reaction to the course. We picked some comments that were expressed by a number of respondents and also unique insightful comments. We then added an observation that provides a related explanation for the comments that represents a relevant view by the authors of this paper.

\section{Emergency Management Master Level Courses}

\section{Professional Characteristics and Organizational Practices for EM: Rating 6.41(SD 1.02) Comments 72}

Included topics will be the responsibility of Emergency Managers in various government agencies and nongovernmental organizations, the functions of the various EM agencies, business continuity, and the phases of emergency management from planning through recovery.

\section{Comments made:}

- One would suggest splitting 'business continuity' and "the phases of EM" from this course into a separate course.

- The emergency management and business continuity domains need to merge so as to create a common environment for emergency preparedness, operations, and recovery.

- It would be helpful to include discussion about how organizations operate. For cities, some are strong mayor/weak council, where others are weak mayor/city manager/strong council. How are decisions made; who has power? Why is emergency management on the city/county level more "political", where in health organizations it more "standards" driven?

- It's important to look outside the EM community for professional partners

- Make sure that the professionals currently working in the field are consulted for the curriculum. Do not ask those from the academic world who have just done research and wrote papers.

- Responsibilities are different through different states. Public and private sector have different dynamics that cannot be mixed.

\section{Observations:}

Academics are not trusted to be very relevant by many practitioners. EM in the corporate environment is not a very significant position with the likelihood of joining upper management. Corporations try to avoid involvement in local disasters. Clearly, a lot of what 
are viewed as problems is the long term results of a lack of clear standards for the discipline.

\section{Planning, Foresight, and Risk Analysis: Rating 6.31 (SD 1.12) Comments 57}

This course focuses on planning, risk analysis, and mitigation options to make responses more effective and to reduce the size and difficulties of the recovery effort. The course also addresses how to evaluate the effectiveness of the human and system performance. Included would be analyses of approaches to similar disasters in other locations. This course may need to be modified periodically based upon new findings and advances.

\section{Comments Made:}

- Risk analysis deserves its own class. It's vital to prioritizing efforts and few people have the education to do it properly.

- Representative of advance infrastructure protections and relationship to the whole community in all phases of EM is essential.

- There is a lot on conflicting information, especially when considering law enforcement/intelligence, which focus on "threat assessment" or "security assessment" and confuse that with a broader perspective EM risk assessment.

- A lot of people don't realize the importance of strategic planning; that is, planning for a Plan B and $\mathrm{C}$ if Plan A does not work. Strategic planning is essential.

\section{Observations:}

Too often, Emergency Managers are confined to response and their lack of credentials isolates them from real planning decisions and influencing possible investments in future mitigation of current risks.

\section{Case Studies of Failures in Emergency Management: Rating 6.26 (SD 1.13) Comments 82}

Learning from failures in EM has provided for significant improvements and changes in response and recovery practices. Reports and books on prior disasters will be discussed to provide useful insights and an understanding of prior experiences.

\section{Comments made}

- Using real life examples, both successes and failures, can be the best teaching tools available.

- Must include how American policy, politics, and politicians can and have contributed to EM failures (e.g. Hurricane Katrina).

- Would not focus just on failures - take a broader perspective on the "good, bad, and ugly".

\section{Observations}

The fact that we divide up the problem and give it to a great many different organizations (utilities, private corporations, layers of government, etc.) which no longer plan together invites the development of unexpected problems in most disasters.

\section{Disaster Types and Characteristics: \\ Rating 6.11 (SD 1.30) Comments 97}

With a focus on both natural and manmade disasters, this course will focus on the disasters most likely in the country or region where the course is taught. The content will include challenges and necessary responses for specific types of disasters. Disasters in other areas will also be more briefly addressed to inform those who move to new locations.

\section{Comments made:}

- Concepts of vulnerability, conflicts between protecting people-property-environment

- This does not take into account any risk reduction taken by an organization.

- To some extent, it should cover all types of disasters because EM personnel can be highly mobile these days.

- Please don't use the term "man-made" - "human induced" is the correct adjective.

- One would have thought you want to cover all disasters which are plausible rather than focus on the ones "most likely" which may have small consequences.

- The fact that FEMA is forcing states to write up global warming plans goes against their "disasters start and end locally."

\section{Observations:}

This is going to be a much more involved course than our initial definition indicated. The Emergency Manager needs a clear understanding of the characteristics and properties of any type of disaster and an appreciation of how they impact different environments.

\section{Critical Infrastructures and Their Interactions: Rating 6.07 (SD 1.18) Comments 54}

Understanding all of the critical infrastructures that service a populated area is critical for effective response and planning. Disasters often cause unexpected interactions between these infrastructures, which makes response more difficult. In the United States, the aging of the infrastructure is an additional critical problem which adds to the potential and complexity of failures and disasters.

\section{Comments made}

- Cascading (domino) failures are becoming increasingly frequent because of the integration and interdependencies of infrastructure - lose electricity and you lose the ability to pump gasoline and in turn you lose police cars when they run out of fuel 
and police on foot can't cover the same territory as a mobile patrol, etc.

- This topic is often treated in such a vague manner it brings little utility to professionals in the field.

- What about resilience and how resilience ties into emergency management?

\section{Observations}

Resiliency is the new popular term; however, none of the current resilient cities seemed to have published any serious review of the interactions between infrastructures. Only, New Zealand requires a complete analysis of infrastructure interactions after any major disaster.

\section{Legal, Ethical, and Policy Concerns: Rating 6.02 (SD 1.24) Comments 48}

Topics covered include the legal and ethical (e.g. privacy) issues Emergency Managers face in the development of procedures and policies and their implementations. The primary focus will be on the issues in the location served by the institution, with some comparisons with concerns in other locations as well.

\section{Comments made}

- Course should NOT be customized for a specific location - Major emphasis should be on ethics and communications/classifications. Privacy is not an ethical issue anymore; it is a point of law. Also, privacy concerns fit with response considerations need to broaden the consideration.

- This module should be more oriented to how population perceives emergency planning, and how an emergency planner must better involve population.

- Course should also review local, state, and national laws that authorize public emergency managers (city county ordinances, state statutes, and the Stafford Act/National Law).

\section{Observations}

Ultimately, we need to reach a state where community members and organizations are able to be trained and able to function in a disaster and be an active part of the response function. EM professionals need to be the facilitators of this process.

\section{Security and Terrorism Characteristics and Situations: \\ Rating 5.40 (SD 1.44) Comments 80}

Study of the involvement of Emergency managers in terrorist activity, especially that which has a wide impact (e.g. dirty bomb) or high casualties (e.g. explosion)

Comments made
- All aspects of CBRNE (Chemical, Biological, Radiological, Nuclear, and Explosives) may be added to this area.

- This might be folded into another EM course. Scenarios like dirty bombs are poorly understood, even by "experts", are fantasy scenarios, and are far less likely to happen than industrial accidents or natural disasters. Perhaps terrorism as a class of event could be taught in other courses, but this sort of course runs the risk of elevating terrorism to a higher level than it deserves, and thereby introducing ideas to the curriculum that are often at odds with what professional disaster researchers have learned over the last 70 years.

- Many Emergency Managers need to have a more solid understanding of this than they currently do. For example, many EM's lack understanding of how to protect a crime scene.

\section{Observations}

Degrees in Security and Terrorism are almost as numerous as EM degrees; however, they do not really prepare a student as well for a realistic education especially at the undergraduate level. There are basic conflicts concerning secrecy and the release of information during an emergency.

\section{Public Health and Medical Services: Rating 5.38 (SD 1.47) Comments 82}

Topics in this course will include the characteristics of medical facilities in various types of locations and their ability to respond to various types of disasters. Requirements for responding to different types of disasters (e.g. pandemics, release of poisonous materials) will be included in the course. Public Health courses addressing pandemics that may cross international boundaries will require an international treatment.

\section{Comments made:}

- It is important for managers to know what resources are available and with whom they can collaborate.

- Consideration of mental health issues common to EM needed in description.

- Within this course should be information on the likelihood that these facilities will be available in a crisis (especially events such as earthquakes, tsunamis, hurricanes) and examine possible workarounds if these facilities are rendered inoperable.

\section{Observations}

The lack of real interaction between Medical Facilities and the Emergency Management community has led to many more severe injuries and causalities in major disasters. The growing threat of pandemics is increasing the need to improve the current situation. 


\section{Emergencies in Developing Countries: \\ Ratings 4.77 (SD 1.58) Comments 79}

There is focus on understanding the difficulties that developing countries have in responding to a wide range of disaster types and how they can best manage to cope with such situations. Other topics include the operations of humanitarian organizations and the problems inherent in the movement of large numbers of refugees.

\section{Comments made}

- Yes, the ability of developing countries to respond compared to developed countries is of great interest and should be included. Maybe developed countries could learn from these alternative responses and use them as part of a multi-tiered emergency plan.

- Ebola in Africa is a fine example.

- Emergency program in developing countries like Bangladesh, needs food security, livelihood development, emergency shelter, transportation of relief materials to the disaster victims, emergency water, \& sanitation support etc. should be in the curriculum.

\section{Observations}

Preparedness in the U.S. is dependent upon the state and local government. It can, in a major disaster, turn into a situation more like a developing country.

\section{Fire Fighting Characteristics and Situations: Ratings 4.25 (SD 1.74) Comments 99}

This is study of the range of fire types and what resources are needed to respond to them. What are the desirable mitigation factors which will reduce the likelihood of fires? How does one assess the needed resources and the desirable training for the fire fighters to handle an increasing range of possible emergencies? This course is for information and analysis purposes and is not intended to provide the physical training needed by firefighters.

\section{Comments made}

- What about prevention first, mitigation second as your approach. Will this course include other physical hazards other than firefighting, e.g. explosion?

- The focus of this course should be on how Emergency Managers "interact" (coordinate, collaborate, oversee) with firefighters before, during, and after emergencies.

- One would keep this at the policy and strategic level. EM professionals do not need to know detailed fire-ground tactics.

\section{Observations}

Traditionally, communications between the firefighting organization and the EM organization seem to be only at the top level of these organizations.
This means there are many instances where there is a lack of adequate lower level cooperation in all the phases of the emergency management process. In some cases, there have been actual conflicts in some urban environments.

\section{IS Courses for an Emergency Management Master's Concentration in IS}

\section{Social Media for Emergency Management Information Systems (EMIS): Rating 5.89 (SD 1.33) Comments 42}

As a communication medium, Social Media is currently used, and has the potential for use, for dissemination and collection of information between government agencies, public entities, and a mixture of the two. Each paradigm has both challenges and opportunities in all phases of Emergency Management. Use by official organizations (e.g. government, NGOs) as well as the public and the benefits and risks of integrating the two will be addressed in the context of processes, procedures, policies, technical requirements, and attitudes.

Comments made:

- Not just the dissemination of info, but use of information gleaned from social media and turning it into intelligence.

- Social Media will either make or break an EM organization.

- There is nothing worse than seeing a country fail to utilize social media during a crisis. It's low hanging fruit.

\section{Observations:}

Many EM organizations today forbid the use of social media systems during a disaster. If local community systems are created that can have software added for handling all sorts of emergency problems than a lot more can be done than current social media would allow. This should include a local Geographic IS (GIS) capability.

\section{Decision Support Systems for Emergency Management: \\ Rating 5.75 (SD 1.45) Comments 49}

This course, requiring the proposed course on Requirements for Emergency Management Information Systems as a prerequisite, will focus on the support IS can provide for decision making in all phases of an emergency. It will address individual and group decision processes and how an IS can support them (e.g. the types of information needed, mitigating possible biases through feedback and analysis). All decision makers will be considered. Review of the 
literature and case studies will uncover ways IS can be improved to better support decision making.

\section{Comments made}

- So long as there is a full understanding of humanistic manners of decision making as well.

- Don't forget decision making without IS support systems too. Maybe a comparison between them would be useful to include in the course.

- One would focus more on the "requirements" aspects of DSS for crisis management and the discussion on what types of decisions that need computer support (virtually all).

\section{Observations}

The system has to know how to determine the group of people that need to deal with a specific problem and create and facilitate the communications of that group. The respondents are concerned about the computer solving the problem without human involvement.

\section{Requirements for EMIS: Rating 5.61 (SD 1.43) Comments 57}

A focus on the functions a computer system must be able to perform to assist humans in dealing with emergency situations most effectively and efficiently.

\section{Comments made}

- How to cite properly information. It's painful to read reports or briefs to local elected officials that have little to no cited primary sources.

- Mitigation planning, floodplain science, recovery operations, first responder, and volunteer psychology/sociology, continuity of operations planning

- None of the courses seems to address data merging or joint characterization which is at the crux of EM. Information is political and a course on collaboration, data systems, and how information is interpreted by different audiences is essential to this degree.

\section{Observations}

The integration of information from many different and unexpected sources into useful insights for particular situations is critical. A real EMIS system is really a communication system that can discover what needs to be put together and to where it should go.

\section{Collaborative Problem solving using EMIS: Rating 5.50 (SD 1.50) Comments 29}

The focus of this course is to be able to evaluate systems and tools that provide for dynamic collaborative solving methods and process in emergency management. As any crisis, or potential crisis, is of mutual interest to different professionals, they need the support of tools that will allow a quick collaborative response to unexpected response problems.

\section{Comments made}

- Mutual collaboration is required for disaster response.

- This sounds very compelling, to be able to organize across multiple organizations to respond to a major event.

- The Delphi method and other techniques should be discussed.

- It is a trend the EM is taking.

- We promote the disbanding of silos amongst all who are responsible for EM, regardless of origin.

Observations

While a lot has been written and even demonstrated on the use of computers for EM problem solving it is still somewhat new to the current EM community [13, 14].

\section{A Master's Thesis:}

\section{Rating 5.44 (SD 1.63) Comments 54}

(Programs with focus on EMIS only) A one or two semester course with representation on the committee from a computing sciences department, if possible. Departments are encouraged to hold regular seminars for all masters students at which practitioners will be invited to speak about their real world experience. The regularity and ability of a department to do this will depend upon many factors such as the size of the department.

\section{Comments made}

- Thesis or project?

- Unpaid coop experience in an organization?

- More knowledge in a related field?

\section{Observations}

Those instructors that have done research can usually recognize in a Masters Course those that have potential to go on do Ph.D. quality research. Most students in this type of program are currently part time and not likely to go on immediately to the Ph.D. level. This provides an opportunity to let the student gain confidence in research in their other field but related to EM. It may encourage students at some future time to proceed to a part time $\mathrm{PhD}$ program. The hidden problem here in most academic institutions is interdisciplinary cooperation between different departments.

\section{Advanced topics in IS for EM:}

\section{Rating 5.38 (SD 1.56) Comments 33}

A survey course to examine the newest trends in IS for Emergency Management. A basic understanding of such systems and tools as modeling and simulation, Geographical Information Systems (GIS), and analytic tools will be discussed. Each semester another topic or type of system can be the focus of the semester. 
Institutions may choose topics that are especially germane to their constituency and location.

\section{Comments made}

- Modeling and GIS both deserve more focus.

- The importance of communications and relationships with other EMs in the region and data sources nationally.

- New technological options

\section{Observations}

A typical exercise for this type of course is giving each student different new professional publications to read and report back to the class in a write up and presentation.

\section{Participatory Databases for EMIS: Rating 5.27 (SD 1.50) Comments 30}

Databases that people can contribute to and can extract useful information from as well as engage in topical discussions are the topic of this course. Many of these databases will have public access and/or will be geographically oriented. Being able to set up and administer these databases and applications will be a requirement for many Emergency Managers. A basic understanding of the necessary roles and activities in database management is the goal of this course.

\section{Comments Made}

- The majority of EM agencies will be hard pressed both in skills and funding resources to sustain, much less acquire sophisticated systems. However, as an academic course the information would be useful.

- One can see this tied to GIS.

- The public wants more information and we should be on top of any type of database systems to which the public has access.

\section{Observations}

In some New Zealand urban locations, a person may report to one GIS database system any problem he would send to any utility, any government agency, and any emergency service he uses. The citizen can see the queue he or she is in. All local problems show up so that if there is a number of natural gas problems close to one another (e.g. after a minor earthquake) a potential problem is immediately visible. Clogged roadways are also obvious.

\section{Information Systems Evaluation: \\ Rating 5.17 (SD 1.54) Comments 30}

Overview and practice with qualitative and quantitative methods for involving users to obtain feedback on usability and usefulness of a system. This includes interviews, "thinking out loud," protocols, surveys, and experiments.

\section{Comments made}

- Would include techniques/tools for how the emergency manager when faced with an overwhelming amount of information during an emergency is able to quickly, accurately, sift through, organize, prioritize and provide essential information to decision makers.

- Make sure you are defining a system as a collection of tools that assist humans, not some grand unified computer to solve all our problems.

- In my experience the connection between a user base and the IT support organization is universally absent in government organizations.

\section{Observations}

Most of the comments reflect a lack of understanding that this would be a research methods course. It is important to regularly measure if a current EM system is still relevant to the tasks it is dealing with and if it needs new capabilities and improvements to existing capabilities. Giving EM professionals some idea of what constitutes a good system and research methods to use to recognize current difficulties would be very beneficial to the evolution of systems.

\section{Human Computer Interface Design for EMIS: Ratings 5.10 (SD 1.59) Comments 30}

The properties of a computer and information interface that allow humans, as individuals and groups, to focus on complex situations and gather necessary information to determine timely solutions to difficult and rapidly changing events. The similarities and differences in HCI requirements for different systems (e.g. Command and Control, mobile devices deployed in the field) will also be discussed.

\section{Comments made}

- We really need to ensure the systems aren't just easy to use when calm but also when under stress.

- You also have to stress that when all this high tech stuff fails, how to fall back on the old ways.

- Data cannot be added that fast to keep up with an ever changing event. It is a tool for recovery.

- Needs to emphasize the human decision-making element with IS as an enhancement thereof.

\section{Observations}

Most of the comments are not about interface design but rather about the role of information systems in disaster management. There is clearly a lot of mistrust in the use of computers during response. Gathering information and making decisions is still often via face to face and verbal communication for a lot of the EM process. Many of the current systems are not really designed to handle the group decision process in an emergency. Once the required role of timely collaborative problem solving in the online environment is recognize, interface design would focus 
on what is necessary to make that an easy and clear task to the users.

\section{Sensor and Network Systems for EMIS: Rating 5.02 (SD 1.53) Comments 32}

The use of sensors and other field devices to gather timely information about a given situation in order to respond quickly to crisis will be addressed. Both hardware sensors and computing devices used by responders, other professionals, and citizens will be discussed.

\section{Comments made}

- Has merit - tap into resources already in place by non-EM agencies.

- This could include non-traditional devices such as an aerial vehicle.

- The bigger challenges are in information governance, integration, and the processes of sharing, not the limitations of sensors and systems.

\section{Observations}

This is a rapidly advancing area that will prove to be very useful for many types of disaster situations. The EM professional should be prepared to take advantage of it as it evolves.

\section{General Comments}

The following are general comments of some significance made by the participants in the 183 general comment options after they did the evaluation of all the courses:

Comments Made

- As the severity of the event increased and the needs of the affected community eventually greatly surpassed the response capacity of the emergency management organizations, the trained professionals reacted by directing their resources to the most severe problems in the community. The problem we observed was that the officials also isolated themselves and failed to communicate with the affected population. I believe that training of emergency response managers could, and should, be modified to handle better the transition from day-to-day emergencies, when a command and control structure is suitable, into disasters, when the command and control structure breaks down, and the entire community must organize a more decentralized response to meet needs.

- Plate Tectonics and or Seismology, Hydrology, Meteorology, architecture and structural engineering should be covered as it is critically important for a disaster manager to know what type of hazards can arise from them.
- Every emergency or disaster is similar, but are also very different at the same time. No two tornados or floods are the same. They all typically have the same characteristics but all have different resources and responses needed. This is an area that I do not see students coming out of college with an understanding of.

- Courses on how to collaborate and network with local, state, and federal agencies along with private and NGO's. This is still lacking and needs much work in the EM field. Another topic would be EM for rural areas. Frankly, many curriculums and standards are set for large Metropolitan areas. Rural areas are a completely different animal that lacks a lot of resources.

- A significant portion of the literature on teams and group dynamics is based on the study of emergency response teams - especially on failures due to dysfunctional interpersonal dynamics. Any graduate degree in EM should address teamwork, collaboration, and interpersonal communications both in concert with and separate from IT.

- Decision making under stress conditions should be required, included practical exercises of decision making under stress.

- The lack of a strong course in disaster social science would simply lead to a new cadre of professional emergency mangers who would continue to believe the myths and legends currently taught and believed in the police and fire services-myths that are dangerously wrong.

- We really need to ensure the systems aren't just easy to use when calm but also when under stress.

- Interpersonal Communication Skills in Emergency Management - Theory and practice for human communications, with special emphasis on effective communication during high stress and emergency situations

\section{Observation:}

Actually, "Threat Rigidity" is a very well-known property that Emergency Managers can suffer when they are under sufficient stress. It has a long history with many studies back in the 60' and 70' but not well known today. An excellent review can be found in a 2010 paper [8]. In severe disasters where tough decisions have to be made not being able to get good feedback on whether the decisions being made are working or not working is a major cause of such stress. It should come up in some of the courses like the Case Studies Course. The problem of stress carries over to politicians and managers and sometimes poor plans are a major cause factor. 


\section{Conclusions and Limitations}

Clearly, there is a need for standards that will give those in Emergency Management the same status and influence that occurs for those professional fields such as management, engineering, the natural and social Sciences. There is a new effort in educational standards for IS and IT involving both AIS and ACM [9]. They are definitely interested in EM courses covering IS and IT. The new committee recently sent out requests for information. We have and will be feeding all the papers produced by this effort directly to that task force.

In recent years, the gap in emergency management education resulted in the creation of many training exercises, and even games, to allow individuals to gain further knowledge of what to do in complex situations $[1,3]$. This has probably been the most beneficial for local government officials and some community members.

There are certain very specific limitations in terms of what we could not include in the survey. For example, all courses, where possible, should illustrate examples of creativity in Emergency Management. A great many significant responses in emergency response are due to individual or group creative processes. For example, New Zealand, with a yearly surplus of shipping containers, has demonstrated at least four separate applications for their use after both earthquakes and floods:

- $\quad$ Supporting weakened buildings with container stacks

- Providing supply and distribution sites for materials

- $\quad$ Protection from falling debris in walking paths

- Flood control gates against flow of water out and preventing high tide inflows

In the 2011 tragedy in New York City, a New Jersey National Guard sergeant decided, on his own, to ask at the local office of the ferries to make one of them available as an ambulance to move casualties to the emergency hospital being established across the Hudson on the New Jersey shore.

The lesser rating of the information system courses eight and nine we feel may be due to a lack of a larger number of senior professionals in Information Systems. Information Systems courses supporting professional groups need regular updating and improvements to remain current for professionals in areas that are undergoing change and development. Information System professionals need to know how to evaluate the systems by methods that involve users and have to be able to plan the evolution of such systems. Without this process, systems will become obsolete [8].

One example, for severe disasters, is the current need to incorporate the digitalization of all inputs from all vocal reports from citizens and participants so they can be provided for any situation requiring diverse participants to deal with problems that cut across many different concerns. An example would be the need to assign a limited number of portable electrical generators to a much larger number of organizations requesting the use of such equipment. Most serious problems in major emergencies involve many different organizations and roles $[13,14]$. The addition of many types of sensors to the situation increases the magnitude of the problem for future disasters.

One of the authors has been following Emergency Management online discussions and message lists since 2004. There was a discussion that ran on for over a year by some very experienced Emergency Managers who had a lengthy discussion on a "motto of Emergency Managers." The motto they all agreed upon testifies, in our mind, to the difficulties Emergency Managers face without the recognition of professional abilities and the status that comes with standardized graduate degrees in professional areas.

The only time they may have command authority is during a disaster, but even then, it may only be advisory to the leadership. They rarely seem to be able to influence decisions on major mitigation practices, policies, and investments. They often know what went wrong and why but rarely can they make that knowledge public. All that we feel leads to the motto that they came up with.

\section{We, the willing, led by the incompetent to do the impossible for the ungrateful, have done so much for so long with so little, we are now capable of doing practically anything with nothing.}

The best explanation for the above problems existing can be found in the outstanding 1976 paper by Turner [10]. The fact that they cannot turn the tide, Turner makes clear, rests with prior lack of professional standing that would match that of most scientists, engineers, auditors, or medical professionals. What we are really missing in this area of Emergency Management is Emergency Manager Auditors [13]. It took us about 30 years to evolve Information System Auditors to meet the continuing threat of attacks on Computing Systems of all types and that is still a rapidly evolving discipline.

Acknowledgements: to the Center for Integrated Emergency Management, University of Agder, 
Norway, and to Jose J. Gonzalez for partial support of Murray Turoff's efforts on this paper.

\section{References}

[1] Alexander, D. (2003). Towards the development of standards in emergency management training and education. Disaster Prevention and Management: An International Journal, 12(2), 113-123.

[2] FEMA 2015. http://www.training.fema.gov/hiedu/collegelist/. Retrieved October 3, 2015.

[3] Hosseini, M., \& Izadkhah, Y.O. (2010). Training emergency managers for earthquake response: challenges and opportunities. Disaster Prevention and Management: An International Journal, 19(2), 185-198.

[4] Lucus-McEwen, Valerie. "What You Should Know About Emergency Management Degrees.” Emergency Management. 2011.

http://www.emergencymgmt.com/training/Emergency$\underline{\text { Management-Degrees-Careers.html?page }=1 \& 1}$

[5] H.A. Linstone, M. Turoff, Delphi: a brief look backward and forward, Technol. Forecast. Soc. Change (2010), doi:10.1016/j.techfore.2010.09.011.

[6] Linstone, H.A., M. Turoff, The Delphi Method (online $\underline{\text { http://is.njit.edu/turoff } 6 / 9 / 16)}$

[7] Plotnick, L. ,M. Turoff, Starr Roxanne Hiltz, Lili Yang, and Victor A. Bañuls. Curriculum guidelines for master's level programs in information systems for emergency management. Proceedings, ISCRAM 2016 Conference, Rio de Janeiro, Brazil, May 2016; Tapia, Antunes, Bañuls, Moore and Porto, eds...

[8] Plotnick, L. and M. Turoff, Mitigating Threat Rigidity in Crisis, in Information Systems for Emergency Management, Chapter 4 (van de Walle, Bartel, Murray Turoff, and Starr Roxanne Hiltz, eds.), a volume in the Advances in Management Information Systems monograph series (Editor in Chief: Vladimir Zwass), M. E. Sharp, 2010.

[9] Topi, H., Valacich, J. S., Wright, R. T., Kaiser, K., Nunamaker Jr, J. F. Sipior, J. C., \& de Vreede, G. J. (2010). IS 2010 Curriculum guidelines for undergraduate degree programs in information systems. Communications of the Association for Information Systems, 26(1), 18.

[10] Turner, B.A., The organizational and interorganizational development of disasters, Adm. Sci. Q. 21 (1976) 378-397..

[11] Turoff, M. (2014). Emergency Management Education and ISCRAM. Proceedings of the 11th International ISCRAM Conference. University Park, Pennsylvania, USA, May 2014, S.R. Hiltz, M.S. Pfaff, L. Plotnick, and A.C.
Robinson, eds.

[12] Turoff, M., Bañuls, V.A., Plotnick, L., Hiltz, S.R., Ramirez, M., Collaborative Evolution of a Dynamic Scenario Model for the Interaction of Critical Infrastructures, Proceedings of the ISCRAM 2015, Kristiansand, May 24-27.

[13] Turoff, M., Chumer M., Hiltz, R., Klashner, R., Alles, M., Vararheyi, M., and Kogan, A., (2004b) Assuring Homeland Security: Continuous Monitoring, Control \& Assurance of Emergency Preparedness, Journal of Information Technology Theory and Application,(JITTA), 6, $3,1-24$.

[14] Turoff, M., Chumer, M., Van de Walle, B., and Yao, X., (2004a) The Design of a Dynamic Emergency Response Management Information System (DERMIS). Journal of Information Technology Theory and Application, (JITTA), $5: 4,1-35$. 